OPEN ACCESS

Edited by:

Hasan Fevzi Batirel,

Marmara University, Turkey

Reviewed by:

Maria Rodriguez,

Clínica Universidad de Navarra, Spain

Miroslav Janik,

University Hospital Bratislava, Slovakia

${ }^{*}$ Correspondence:

Baofu Chen

986725634@qq.com

Specialty section:

This article was submitted to

Thoracic Surgery,

a section of the journal

Frontiers in Surgery

Received: 10 September 2021

Accepted: 07 October 2021

Published: 03 November 2021

Citation:

Wang $X$, Guo $H, H u Q$, Ying $Y$ and

Chen B (2021) Efficacy of Intraoperative Recurrent Laryngeal

Nerve Monitoring During Thoracoscopic Esophagectomy for Esophageal Cancer: A Systematic Review and Meta-Analysis.

Front. Surg. 8:773579

doi: 10.3389/fsurg.2021.773579

\section{Efficacy of Intraoperative Recurrent Laryngeal Nerve Monitoring During Thoracoscopic Esophagectomy for Esophageal Cancer: A Systematic Review and Meta-Analysis}

\author{
Xinxin Wang, Haixie Guo, Quanteng Hu, Yongquan Ying and Baofu Chen* \\ Department of Thoracic and Cardiovascular Surgery, Affiliated Taizhou Hospital of Wenzhou Medical University, Taizhou, China
}

Background: Recurrent laryngeal nerve paralysis (RLNP), a severe complication of mini-invasive esophagectomy, usually occurs during lymphadenectomy adjacent to recurrent laryngeal nerve. This systematic review and meta-analysis aimed to evaluate the efficacy of intraoperative nerve monitoring (IONM) in reducing RLNP incidence during mini-invasive esophagectomy.

Methods: Systematic literature search of PubMed, EMBASE, EBSCO, Web of Knowledge, and Cochrane Library until June 4, 2021 was performed using the terms "(nerve monitoring) OR neuromonitoring OR neural monitoring OR recurrent laryngeal nerve AND (esophagectomy OR esophageal)." Primary outcome was postoperative RLNP incidence. Secondary outcomes were sensitivity, specificity, and positive and negative predictive values for IONM; complications after esophagectomy; number of dissected lymph nodes; operation time; and length of hospital stay.

Results: Among 2,330 studies, five studies comprising 509 patients were eligible for final analysis. The RLNP incidence was significantly lower (odds ratio [OR] 0.33, 95\% confidence interval [Cl] 0.12-0.88, $p<0.05$ ), the number of dissected mediastinal lymph nodes was significantly higher (mean difference 4.30, 95\% Cl 2.75-5.85, $p<0.001$ ), and the rate of hoarseness was significantly lower (OR $0.14,95 \% \mathrm{Cl} 0.03-0.63, p=0.01$ ) in the IONM group than in the non-IONM group. The rates of aspiration $(O R 0.31,95 \% \mathrm{Cl}$ $0.06-1.64, p=0.17$ ), pneumonia (OR 1.08, 95\% Cl 0.70-1.67, $p=0.71$ ), and operation time (mean difference $7.68,95 \% \mathrm{Cl}-23.60-38.95, p=0.63$ ) were not significantly different between the two groups. The mean sensitivity, specificity, and positive and negative predictive values for IONM were 53.2\% (0-66.7\%), 93.7\% (54.8-100\%), 71.4\% (0-100\%), and 87.1\% (68.0-96.6\%), respectively.

Conclusion: IONM was a feasible and effective approach to minimize RLNP, improve lymphadenectomy, and reduce hoarseness after thoracoscopic esophagectomy for esophageal cancer, although IONM did not provide significant benefit in reducing aspiration, pneumonia, operation time, and length of hospital stay.

Keywords: esophagectomy, esophageal cancer, recurrent laryngeal nerve monitoring, lymphadenectomy (LA), mini-invasive 


\section{INTRODUCTION}

Thoracoscopic radical esophagectomy is an important surgical approach in esophageal cancer, and lymphadenectomy during esophagectomy is necessary because lymph node metastasis is common in patients with esophageal cancer. Lymph nodes along the recurrent laryngeal nerve (RLN) is a common site of metastasis, and radical dissection of lymph nodes along bilateral RLNs is important for improving patient prognosis (1-6). However, injury to RLN, which usually occurs during lymphadenectomy, can lead to RLN paralysis (RLNP), a cause of hoarseness and a risk factor for aspiration and pneumonia after surgery (7). The various causes of RLNP include thermal damage, compression, ischemia, and towing among the various causes of RLNP. The reported rate of RLNP during esophagectomy ranges from 14.0 to $76.2 \%$ (8-11). Protection of the RLN during surgery is important in preventing complications and aiding in patient recovery. Intra-operative nerve monitoring (IONM), which can identify nerves and is widely utilized in thyroid surgery, has been demonstrated as a good approach for protecting RLN (12-15). Recent studies examining the utility of IONM in esophagectomy reported its feasibility and efficacy in protecting the RLN (1620). However, studies focusing on the utility of IONM as a method are limited and the number of patients included in these studies remains low. Therefore, we performed a systematic review and meta-analysis to elucidate the impact of IONM on protecting the RLN during thoracoscopic esophagectomy for esophageal cancer.

\section{MATERIALS AND METHODS}

\section{Search Strategy}

A literature search of PubMed, EMBASE, EBSCO, Web of Knowledge, and Cochrane Library until June 4, 2021 was conducted using the terms "(nerve monitoring OR neuromonitoring $\mathrm{OR}$ neural monitoring $\mathrm{OR}$ recurrent laryngeal nerve) AND (esophagectomy OR esophageal)." Patients who were diagnosed with esophagus cancer and underwent thoracoscopic esophagectomy were included for study. The outcome of RLNP were compared in the IONM and nonIONM group. Studies must be retrospective or prospective case control studies.

The inclusion criteria were studies which included patients who underwent thoracoscopic esophagectomy for esophageal cancer and compared patients evaluated with IONM (IONM group) to those not evaluated with IONM (non-IONM group) and reported the outcome of RLNP. Following were the exclusion criteria: (1) articles using duplicated data from the same study, (2) studies that did not directly compare between IONM and non-IONM, (3) articles with only an abstract and no full text, and (4) articles not in English. Relevant articles were also identified through the reference lists of relevant review articles.

\section{Data Extraction}

Data were independently retrieved from the identified studies by two authors (XW and HG). Consensus was reached by discussion in cases of disagreement. The following data were retrieved from the studies: first author; country; publication year; study design; number of patients; sex; smoking history; location of tumor; pathological type; prior therapy; cancer stage according to the American Joint Committee on Cancer guidelines; incidence of RLNP; complications including aspiration, pneumonia, and hoarseness; number of dissected lymph nodes; operation time; time of thoracic procedure; and length of hospital stay.

\section{Quality Assessment}

The quality of included studies were assessed using the Newcastle-Ottawa scale, and a Newcastle-Ottawa scale score of $>6$ were used to define high-quality studies. The assessment was independently performed by two authors (QH and $\mathrm{YY}$ ), and a third author $(\mathrm{BC})$ was consulted to settle disagreements if necessary.

\section{Statistical Analysis}

All statistical analyses were performed using the Review manager software (version 5.3). Between-study heterogeneity was calculated using Higgins' $I^{2}$ statistics (21). Pooled results with an $I^{2}>50 \%$ were considered to exhibit a high degree of heterogeneity, and the random-effects model was used to estimate. A fixed-effects model was used in studies with a low degree of heterogeneity. Sensitivity analysis was performed in the presence of a high degree of heterogeneity. Pooled odds ratios (ORs) and the corresponding 95\% confidence intervals (CIs) were estimated for dichotomous outcomes, and mean differences were estimated for continuous outcomes. The Mantel-Haenszel and inverse variance methods were used for the analysis of dichotomous and continuous outcomes, respectively. Publication bias was qualitatively estimated using funnel plots. Mean and standard deviation of samples were estimated using sample sizes, medians, ranges, and/or interquartile ranges, as described by Wan et al. (22). The overall effect was considered statistically significant with a two-sided $p<0.05$.

\section{RESULTS}

\section{Search Results}

The literature search of the five electronic databases included in the study identified a total of 2,649 studies fulfilling the inclusion criteria. After preliminary screening, 31 studies were retrieved to assess eligibility. Of these, 12 studies which did not compare IONM with non-IONM (23-34). Three case reports on IONM (35-37), one letter to the editor (38), and two reviews $(39,40)$ were excluded. Additionally, four meeting abstracts lacking full texts (41-44), two studies which utilized data from the same study $(45,46)$, and two studies which were not in English $(47,48)$ were excluded. Finally, a total of five studies, including three retrospective cohort studies and two prospective cohort studies, comprising a total of 509 patients undergoing thoracoscopic esophagectomy for esophageal cancer were identified (16-20). In total, there were 240 and 269 patients who underwent surgery with and without IONM, respectively. The PRISMA flow diagram of study identification is presented in Figure 1. 


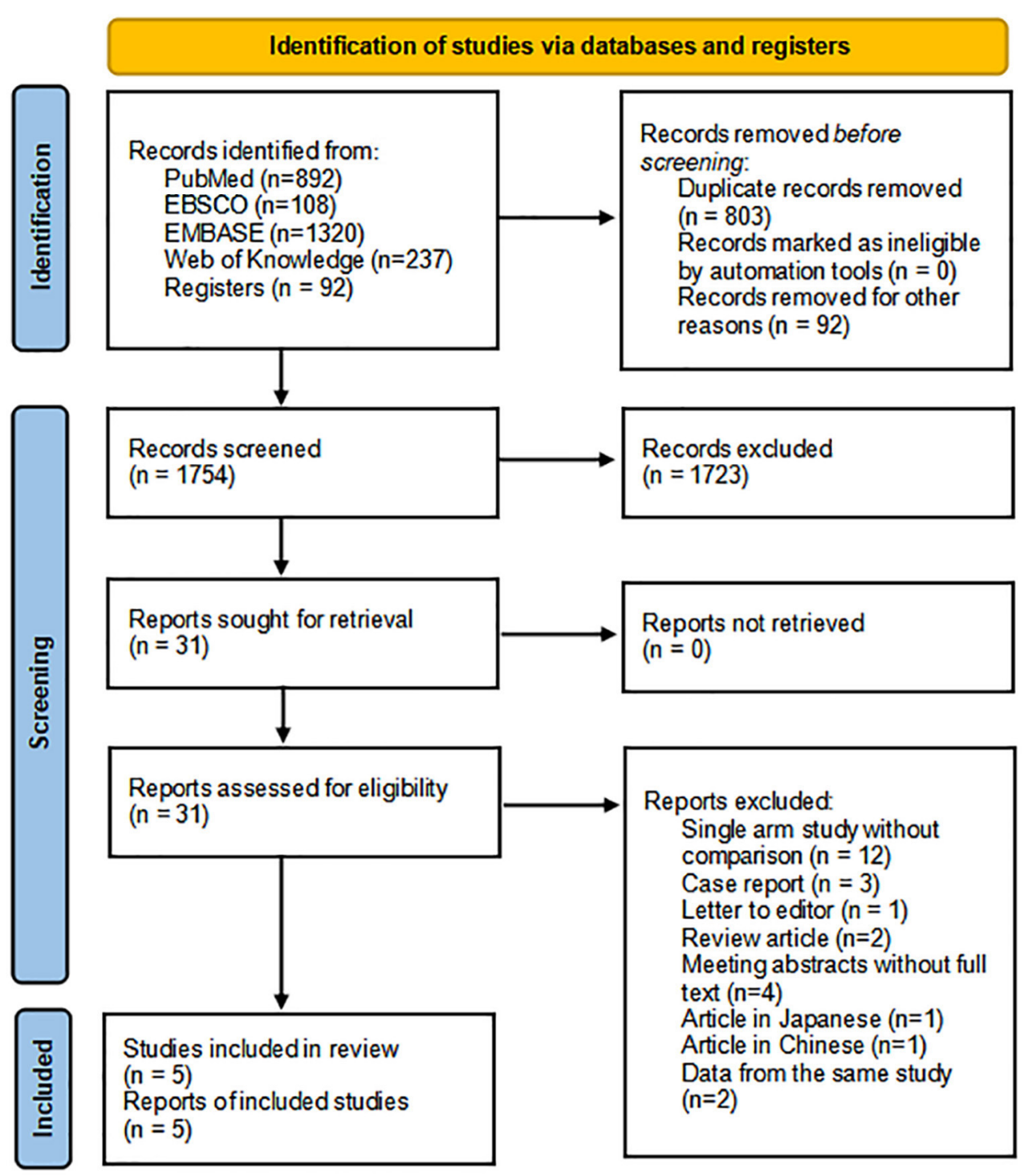

FIGURE 1 | PRISMA flow diagram for study identification.

\section{Patient Characteristics}

The detailed baseline information of patients is summarized in Table 1. Briefly, the mean patient age ranged from 58.9 to 69.5 years in the non-IONM group and from 59.9 to 67.7 years in the IONM group. All studies reported tumor location, and most tumors were located in middle and lower esophagus. All but one of the studies reported the pathological tumor type, and the majority were squamous cell cancer. The percentage of patients who received therapy prior to surgery was not significantly different between the IONM and non-IONM groups in four of the five studies which reported that patients received therapy prior to surgery. All studies reported the cancer stage of patients according to the American Joint Committee on Cancer guidelines, and the cancer stage did not significantly differ between the IONM and non-IONM group.

\section{Outcome of RLNP}

All studies reported RLNP as a surgical outcome. RLNP occurred in both the IONM and non-IONM groups in four studies, except for the study by Zhong et al. The detailed results of IONM are presented in Table 2. The rate of RLNP ranged from 0 to $46.3 \%$ in the IONM group and from 9.8 to $53.3 \%$ in the non-IONM group. The pooled analysis showed that IONM was associated with a significant reduction in the rate of RLNP after thoracoscopic esophagectomy (OR 0.33, 95\%CI 0.12-0.88, $p<0.05$, Figure 2). Three studies reported the correlation between signal loss and postoperative RLNP in the IONM group. The ranges of sensitivity, specificity, positive predictive value, and negative predictive value were $0-66.7 \%, 54.8-100 \%, 0-100 \%$, and $68.0-$ $96.6 \%$, respectively. 
TABLE 1 | Baseline characteristics of patients.

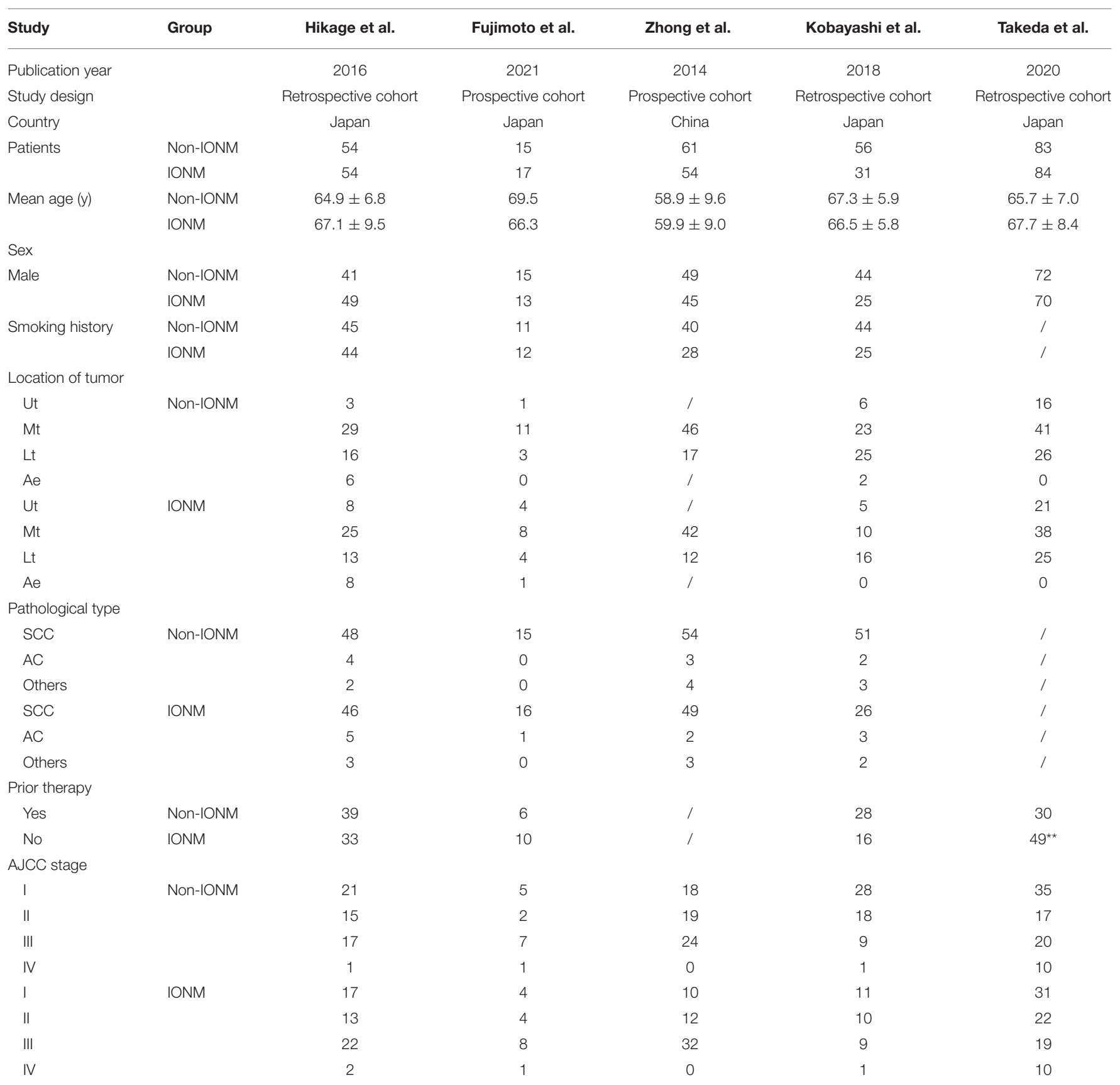

AC, adenocarcinoma; Ae, abdominal esophagus; AJCC, American Joint Committee on Cancer; IONM, intraoperative nerve monitoring; Lt, lower thoracic esophagus; Mt, middle thoracic esophagus; SCC, squamous cell carcinoma; Ut, upper thoracic esophagus.

${ }^{\star}$ The chi-square test was used to compare two groups, and significance was set at a $p<0.05$.

\section{Lymph Node Dissection and Surgical Outcomes}

All studies reported the number of dissected mediastinal lymph nodes during surgery. The detailed information of lymph node dissection and surgical outcomes are presented in Table 3. Briefly, the mean number of dissected mediastinal lymph nodes ranged from 16.0 to 25.8 in the non-IONM group and from 20.6 to 27.9 in the IONM group. The pooled analysis revealed that there were significantly more dissected mediastinal lymph nodes in the IONM group than in the non-IONM group (mean difference $4.30,95 \% \mathrm{CI} 2.75-5.85, p<0.001$, Figure 3). Two studies reported the total number of dissected lymph nodes, including the mediastinal and abdominal lymph nodes. The pooled analysis showed that number of dissected lymph nodes was higher in the IONM group than in the non-IONM group (mean difference 5.61, 95\%CI 3.07-8.15, $p<0.001$, Figure 4). 
TABLE 2 | Results of IONM.

\begin{tabular}{|c|c|c|c|c|c|c|c|c|c|}
\hline \multirow[t]{2}{*}{ Study } & IONM signal loss & No & Yes & No & Yes & Sensitivity & Specificity & PPV & NPV \\
\hline & Vocal cord motion & No & No & Yes & Yes & & & & \\
\hline Hikage et al. ${ }^{\dagger}$ & & 4 & 0 & 43 & 7 & $0.0 \%$ & $86.0 \%$ & $0.0 \%$ & $91.5 \%$ \\
\hline Hikage et al. ${ }^{\ddagger}$ & & 8 & 15 & 17 & 14 & $65.2 \%$ & $54.8 \%$ & $51.7 \%$ & $68.0 \%$ \\
\hline Fujimoto et al. & & / & / & / & / & / & / & / & / \\
\hline Zhong et al. & & / & / & / & / & / & / & / & / \\
\hline Kobayashi et al. & & 2 & 1 & 28 & 0 & $66.7 \%$ & $100.0 \%$ & $100.0 \%$ & $96.6 \%$ \\
\hline Takeda et al. & & 9 & 9 & 60 & 6 & $50.0 \%$ & $90.9 \%$ & $60.0 \%$ & $87.0 \%$ \\
\hline
\end{tabular}

IONM, intraoperative nerve monitoring; PPV, positive predictive value; NPV, negative predictive value.

${ }^{\dagger}$ right side RLN monitoring in thoracic procedure.

‡left side RLN monitoring in thoracic procedure.

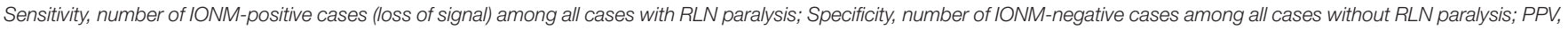

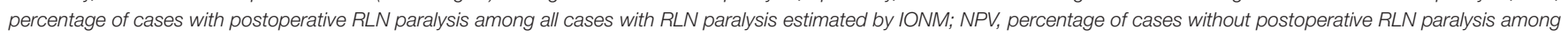
all cases without RLN paralysis estimated by IONM.

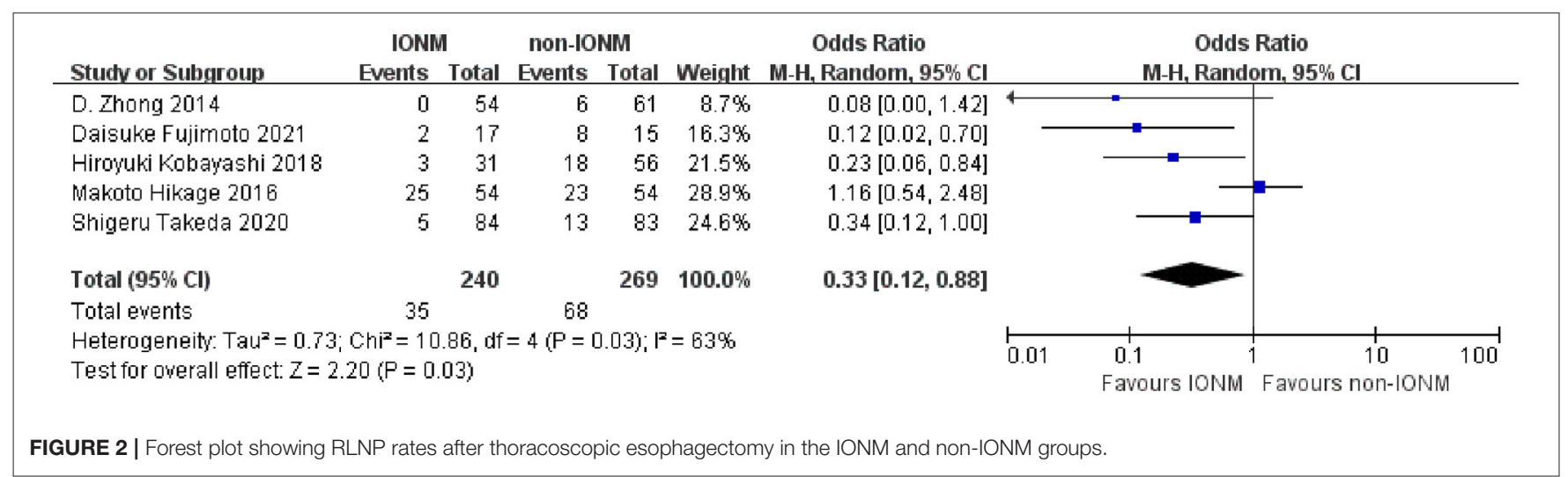

All studies reported the mean operation time, which ranged from 237.8 to $665.3 \mathrm{~min}$ in the IONM group and from 251.1 to $596.7 \mathrm{~min}$ in the non-IONM group. The pooled analysis showed that there was no significant difference in the operating time between the IONM and non-IONM groups (mean difference $7.68,95 \% \mathrm{CI}-23.60-38.95, p=0.63$, Figure 5). The mean length of hospital stay, which was reported in three studies, ranged from 12.5 to 37.3 days in the IONM group and from 16.1 to 60.9 days in the non-IONM group. The pooled analysis of the mean length of hospital stay revealed that there was no significant difference between the IONM and non-IONM groups (mean difference $-10.87,95 \% \mathrm{CI},-24.57-2.83, p=0.12$, Figure 6).

\section{Complications}

All studies reported the rate of pneumonia after surgery, which ranged from 7.4 to $40 \%$ in the non-IONM group and from 13.0 to $25.0 \%$ in the IONM group. The pooled analysis of pneumonia revealed no significant difference in the rate of pneumonia between the IONM and non-IONM groups (OR 1.08, 95\%CI $0.70-1.67, p=0.71$, Figure 7). Four studies reported the rate of aspiration after surgery, which ranged from 9.8 to $46.7 \%$ in the non-IONM group and from 0 to $44.4 \%$ in IONM group. The pooled analysis showed that there was no significant difference in the rate of aspiration after surgery between the IONM and nonIONM groups (OR 0.31, 95\%CI 0.06-1.64, $p=0.17$, Figure 8). Two studies reported the rate of hoarseness after surgery, which ranged from 9.8 to $40 \%$ in the non-IONM group and from 0 to $11.8 \%$ in the IONM group. The pooled analysis showed that the rate of hoarseness was significantly lower in the IONM group than in the non-IONM group (OR 0.14, 95\%CI 0.03-0.63, $p<0.05$, Figure 9).

\section{Heterogeneity and Sensitivity Analysis}

We observed significant heterogeneity in the data on rates of RLNP, aspiration, operation time, and length of hospital stay $\left(I^{2}, 63,78,88\right.$, and $77 \%$, respectively). Therefore, we performed sensitivity analysis by excluding each study and recalculated pooled ORs with 95\%CIs. After excluding the study by Hikage et al., the ORs for RLNP and aspiration were in favor of IONM (OR 0.23 , 95\%CI $0.11-0.48, I^{2}=0 \%$, and OR $0.15,95 \% \mathrm{CI}, 0.05-0.44, I^{2}=0$, respectively). The rate of operation time did not exhibit a significant difference after excluding each study. However, after excluding the study by Kobayashi et al., the OR for length of hospital stay was in favor of IONM (mean difference $-3.65,95 \% \mathrm{CI},-7.06--0.25$, $\left.p<0.05, I^{2}=0 \%\right)$. 
TABLE 3 | Surgical outcomes.

\begin{tabular}{|c|c|c|c|c|c|c|}
\hline Study & Group & Hikage et al. & Fujimoto et al. & Zhong et al. & Kobayashi et al. & Takeda et al. \\
\hline \multicolumn{7}{|l|}{ RLNP } \\
\hline Left & & 19 & 8 & / & 11 & 9 \\
\hline Bilateral & Non-IONM & 1 & 0 & / & 6 & 3 \\
\hline No & & 31 & 7 & 55 & 38 & 70 \\
\hline Bilateral & IONM & 2 & 1 & / & 0 & 1 \\
\hline No & & 29 & 15 & 54 & 28 & 79 \\
\hline \multirow[t]{2}{*}{ Aspiration } & Non-IONM & 17 & 7 & 6 & 16 & / \\
\hline & IONM & 24 & 2 & 0 & 2 & / \\
\hline Pneumonia & Non-IONM & 4 & 6 & 15 & 11 & 19 \\
\hline \multirow[t]{2}{*}{ No. of DMLN } & Non-IONM & $21.3 \pm 14.3$ & 18.4 & $16.0 \pm 5.9$ & $21.2 \pm 9.0$ & $25.8 \pm 9.0$ \\
\hline & IONM & $25.3 \pm 12.1$ & 20.6 & $22.1 \pm 6.5$ & $24.4 \pm 9.0$ & $27.9 \pm 10.0$ \\
\hline \multirow[t]{2}{*}{ No. of positive DMLN } & Non-IONM & $0.6 \pm 1.5$ & ' & $1.4 \pm 1.8$ & / & / \\
\hline & IONM & $1 \pm 2.6$ & / & $2.5 \pm 2.6$ & / & / \\
\hline \multirow[t]{2}{*}{ No. of TDLN } & Non-IONM & $33.4 \pm 15.2$ & I & $24.4 \pm 6.8$ & ' & / \\
\hline & IONM & $37.3 \pm 16.0$ & / & $30.4 \pm 8.4$ & / & / \\
\hline \multirow[t]{2}{*}{ No. of positive TDLN } & Non-IONM & $0.9 \pm 2.4$ & / & $1.7 \pm 2.1$ & / & / \\
\hline & IONM & $2.8 \pm 5.1$ & / & $2.8 \pm 3.0$ & / & / \\
\hline \multirow[t]{2}{*}{ Operative time (min) } & Non-IONM & $593.8 \pm 65.1$ & $596.7 \pm 82.5$ & $257.7 \pm 21.8$ & $251.1 \pm 39.8$ & $549.3 \pm 90.0$ \\
\hline & IONM & $665.3 \pm 116.2$ & $551.6 \pm 83.0$ & $237.8 \pm 29.5$ & $268.3 \pm 51.6$ & $555.5 \pm 92.1$ \\
\hline Time of thoracic procedure & Non-IONM & / & $262.3 \pm 29.6$ & / & / & $332.8 \pm 35.0$ \\
\hline
\end{tabular}

IONM, intraoperative nerve monitoring; RLNP, recurrent laryngeal nerve palsy; DMLN, dissected mediastinal lymph nodes, TDLN, total dissected lymph nodes including mediastinal and intraabdominal lymph nodes.

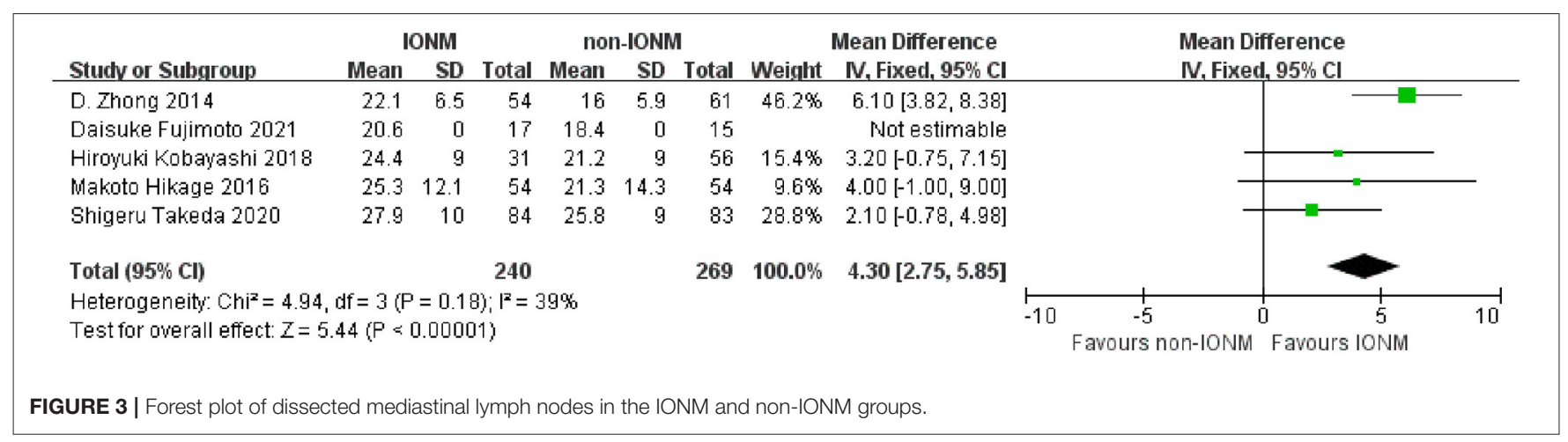




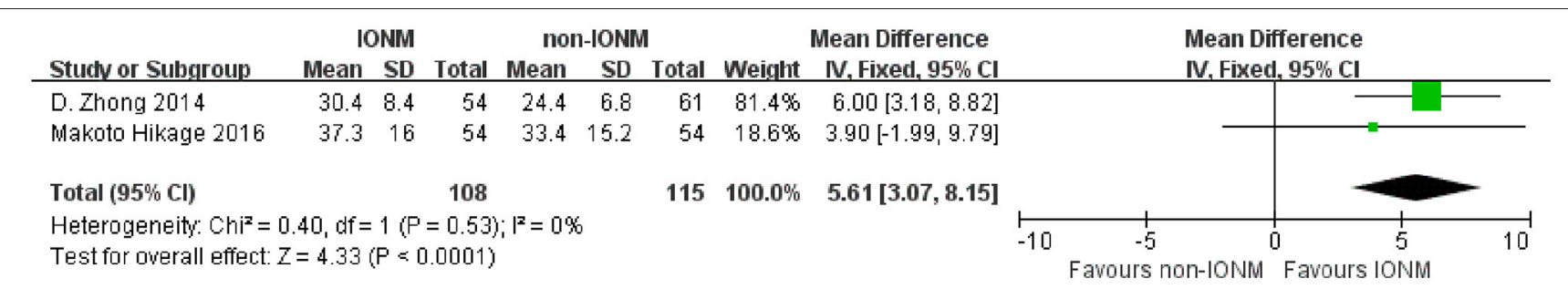

FIGURE 4 | Forest plot of total dissected lymph nodes in the IONM and non-IONM groups.

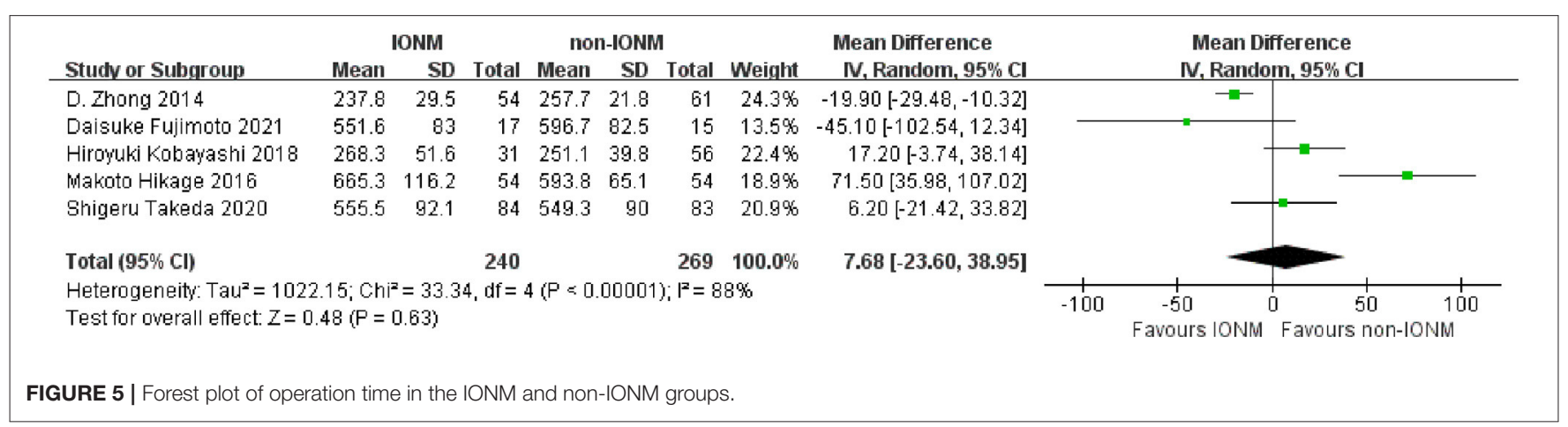

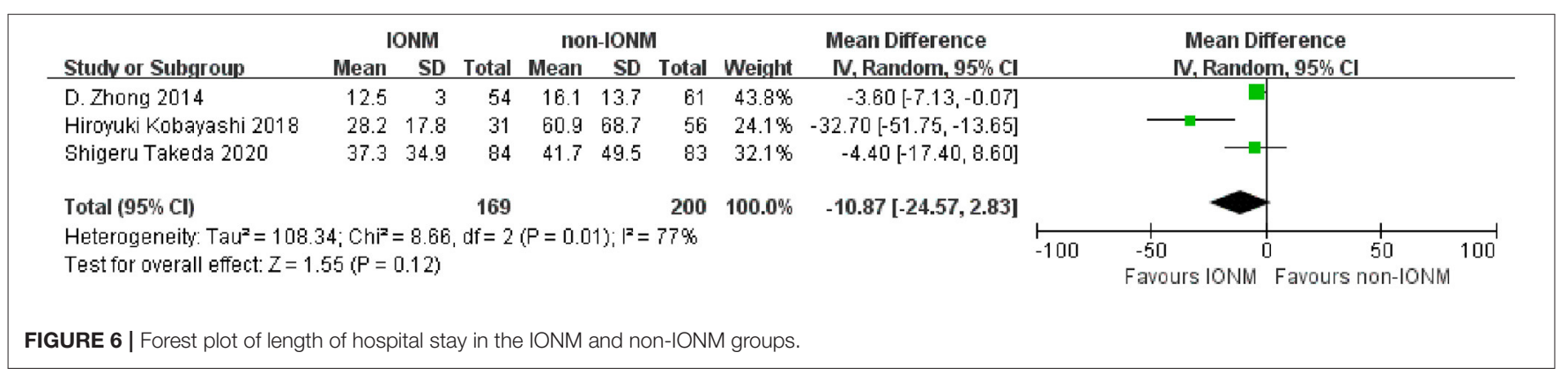

\begin{tabular}{|c|c|c|c|c|c|c|c|c|c|c|}
\hline Studv or Subgroup & $\begin{array}{l}\text { IONM } \\
\text { Events }\end{array}$ & Total & $\begin{array}{l}\text { non-IOI } \\
\text { Events }\end{array}$ & $\begin{array}{l}\text { NM } \\
\text { Total }\end{array}$ & Weight & $\begin{array}{c}\text { Odds Ratio } \\
\text { M-H, Fixed, } 95 \% \mathrm{Cl}\end{array}$ & \multicolumn{4}{|c|}{$\begin{array}{c}\text { Odds Ratio } \\
\text { M-H, Fixed, } 95 \% \mathrm{Cl}\end{array}$} \\
\hline D. Zhong 2014 & 7 & 54 & 15 & 61 & $31.3 \%$ & $0.46[0.17,1.22]$ & & $=$ & F & \\
\hline Daisuke Fujimoto 2021 & 10 & 24 & 4 & 17 & $7.0 \%$ & $2.32[0.58,9.26]$ & & & & \\
\hline Hiroyuki Kobayashi 2018 & 5 & 31 & 11 & 56 & $16.8 \%$ & $0.79[0.25,2.52]$ & & & & \\
\hline Makoto Hikage 2016 & 10 & 54 & 4 & 54 & $8.3 \%$ & $2.84[0.83,9.70]$ & & & & \\
\hline Shigeru Takeda 2020 & 21 & 84 & 19 & 83 & $36.6 \%$ & $1.12[0.55,2.29]$ & & & & \\
\hline Total $(95 \% \mathrm{Cl})$ & & 247 & & 271 & $100.0 \%$ & $1.08[0.70,1.67]$ & & & & \\
\hline Total events & 53 & & 53 & & & & & & & \\
\hline $\begin{array}{l}\text { Heterogeneity: } \mathrm{Chi}^{2}=6.70 \\
\text { Test for overal effect: } Z=\end{array}$ & $\begin{array}{l}\mathrm{df}=4(\mathrm{P}= \\
37(\mathrm{P}=0 .\end{array}$ & $\begin{array}{l}=0.15) ; \\
71)\end{array}$ & $F^{2}=41 \%$ & & & & 0.05 & $\begin{array}{ll}0.2 & 1 \\
\text { Favours IONM }\end{array}$ & $\begin{array}{lc} & 5 \\
\text { Favours non-IONM }\end{array}$ & 20 \\
\hline
\end{tabular}




\begin{tabular}{|c|c|c|c|c|c|c|c|c|c|c|}
\hline Study or Subgroup & $\begin{array}{l}\text { IONM } \\
\text { Events }\end{array}$ & Total & $\begin{array}{l}\text { non-IOI } \\
\text { Events }\end{array}$ & $\begin{array}{l}\text { NM } \\
\text { Total }\end{array}$ & Weight & $\begin{array}{l}\text { Odds Ratio } \\
\text { M-H, Random, } 95 \% \mathrm{Cl}\end{array}$ & & $\begin{array}{r}\text { Odds } \\
\text { M-H, Randc }\end{array}$ & $\begin{array}{l}\text { Ratio } \\
\text { om, } 95 \% \mathrm{Cl}\end{array}$ & \\
\hline D. Zhong 2014 & 0 & 54 & 6 & 61 & $17.0 \%$ & $0.08[0.00,1.42]$ & & (2) & & \\
\hline Daisuke Fujimoto 2021 & 2 & 17 & 7 & 15 & $24.7 \%$ & $0.15[0.03,0.91]$ & & & & \\
\hline Hiroyuki Kobayashi 2018 & 2 & 31 & 16 & 56 & $26.5 \%$ & $0.17[0.04,0.81]$ & & & & \\
\hline Makoto Hikage 2016 & 24 & 54 & 17 & 54 & $31.8 \%$ & $1.74[0.79,3.82]$ & & & & \\
\hline Total $(95 \% \mathrm{Cl})$ & & 156 & & 186 & $100.0 \%$ & $0.31[0.06,1.64]$ & & & & \\
\hline Total events & 20 & & 46 & & & & & & & \\
\hline \multicolumn{6}{|c|}{$\begin{array}{l}\text { Heterogeneity: } \text { Ta }^{2}=2.15 ; \mathrm{Ch}^{2}=13.68, \mathrm{df}=3(\mathrm{P}=0.003) ; \mathrm{I}^{2}=78 \% \\
\text { Test for overall effect: } \mathrm{Z}=1.38(\mathrm{P}=0.17)\end{array}$} & & 0.01 & $\begin{array}{c}0.1 \\
\text { Favours IONM }\end{array}$ & $\begin{array}{rl}1 & 1 \\
\text { Favours nol }\end{array}$ & 10100 \\
\hline
\end{tabular}

FIGURE 8 | Forest plot of aspiration in the IONM and non-IONM groups.

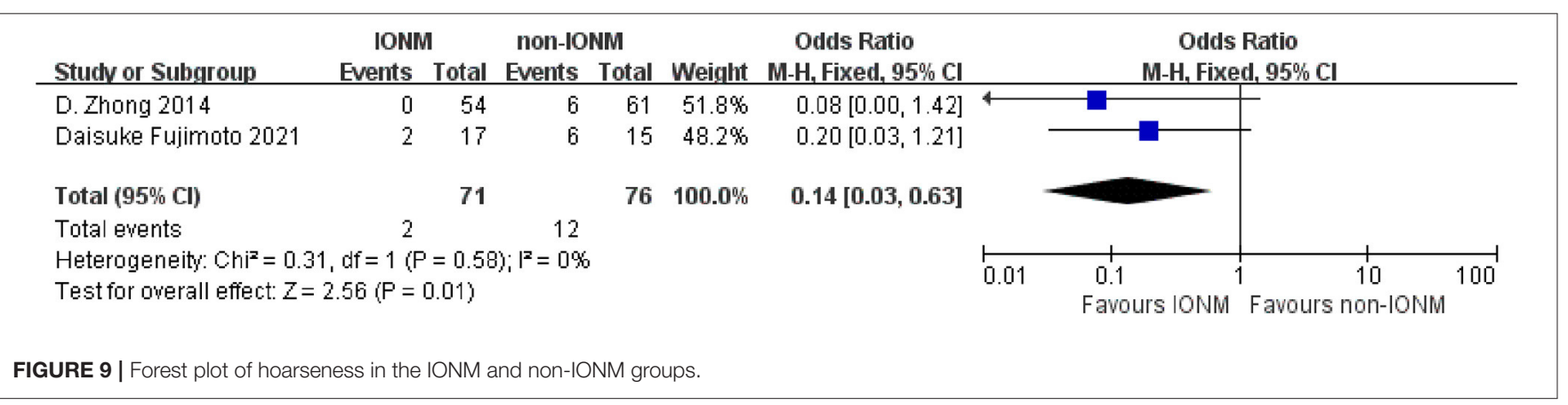

\section{Publication Bias}

The funnel plot for RLNP (Figure 1) revealed that the studies exhibited an almost symmetrical distribution on each side, and an obvious publication bias was not observed.

\section{Quality Assessment}

The quality assessment of the studies is shown in Table 4. Briefly, all studies had a Newcastle-Ottawa scale score of nine, which indicated good methodological quality. No study was excluded because of low quality.

\section{DISCUSSION}

To our knowledge, this is the first systematic review and metaanalysis examining the relationship between IONM and RLNP, which revealed that IONM could significantly reduce the rate of RLNP, improve lymphadenectomy, and reduce hoarseness after thoracoscopic esophagectomy for esophageal cancer. But we did not observe significant differences in operation time, aspiration, pneumonia, and length of hospital stay between the patients evaluated with IONM and those who were not evaluated by IONM during surgery.

The rate of RLNP was significantly lower in the IONM group than in the non-IONM group, although there was a decent degree of heterogeneity. After excluding the study by Hikage et al. (19), the rate of RLNP remained significantly lower in the IONM group without heterogeneity among the studies, which might be explained by the low sensitivity of IONM. In the study by Hikage et al., the surgeon was not familiar with the manipulation of the nerve monitoring system in the first 10 cases and IONM was discontinued in almost $30 \%$ of all patients in the IONM group for a variety of reasons, which might be associated with the lack of reduction in RLNP rate in that study.

The number of dissected mediastinal lymph nodes and all dissected lymph nodes, including mediastinal and abdominal lymph nodes, were significantly higher in the IONM group compared with the non-IONM group. IONM during surgery facilitated the radical dissection of lymph nodes along bilateral RLNs without high risk of injury to the RLN. The ratio of positive total dissected lymph nodes was significantly higher in the IONM group in the study by Zhong et al. (17). Lymph node metastasis is a risk factor for survival $(49,50)$; therefore, radical lymphadenectomy is necessary for accurate cancer staging and improving survival, which was demonstrated in the study.

In the present meta-analysis, the incidence of aspiration was not significantly lower in the IONM group compared with the non-IONM group. Studies previously reported the association of aspiration with RLNP after surgery for esophageal cancer $(7,10,51)$. The reduction in the rate of RLNP after surgery in patients receiving IONM might be partially responsible for the reduced rate of aspiration. Conversely, there was also no significant difference in the rate of pneumonia between the IONM and non-IONM groups. In the study by Zhong et al. (17), the rate of postoperative pneumonia was significantly lower in the IONM group compared with the non-IONM group, which might have been due to the higher percentage of patients with smoking history in the non-IONM group; history of smoking is a proven risk factor for postoperative pneumonia (52). Therefore, largescale studies are warranted to clarify the association between IONM and postoperative pneumonia. 


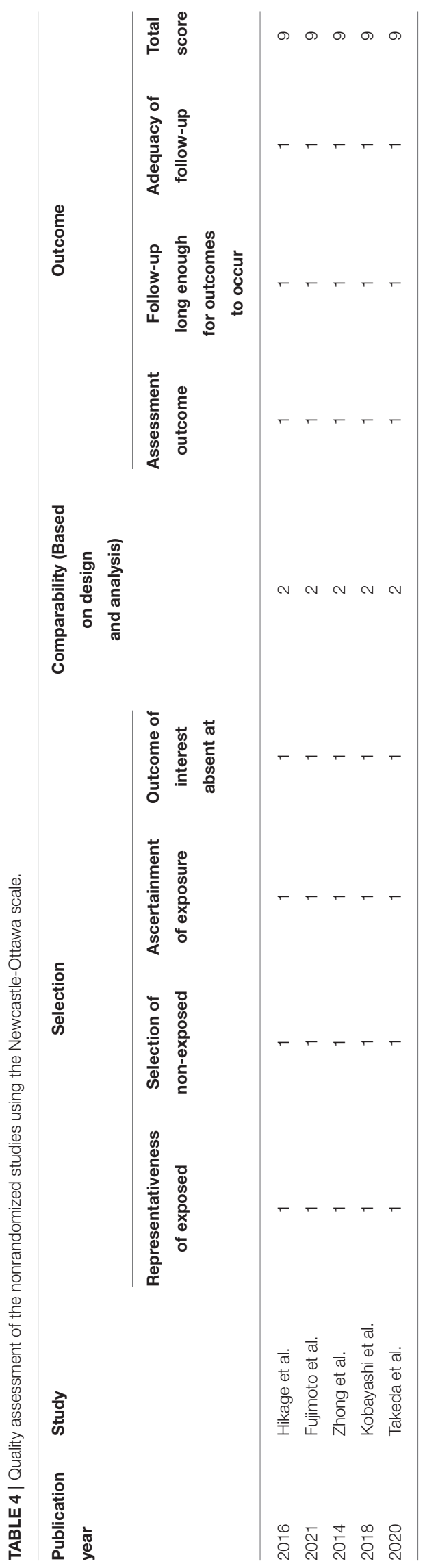

The operation time was not significantly different between the IONM and non-IONM groups, which might be due to radical lymphadenectomy and nerve identification using electrodes during both the thoracic and cervical procedures.

The survival rates of patients in the IONM and nonIONM groups were present only in the study by Zhong et al., in which the Kaplan-Meier analysis indicated that survival was significantly better in the IONM group. This outcome might be associated with the use of radical and complete lymphadenectomy in the IONM group; this approach can identify the metastasis lymph nodes and allows for accurate clinical staging. Of course, additional studies are warranted to elucidate the association between IONM and survival.

To our knowledge, this is the first systematic review and meta-analysis focusing on the impact of IONM on protecting RLN during thoracoscopic esophagectomy for esophageal cancer. However, the present study has several limitations that should be acknowledged. First, none of the studies included in the analysis were randomized. Second, only studies published in English were included and studies reported in other language might have been missed. Third, the small number of studies and patients included in the meta-analysis might not be an accurate representation to assess the impact of IONM on RLNP. Fourth, there was a decent degree of heterogeneity in the current study results, which should be interpreted with caution. Finally, other factors such as ethnicity, prior therapy and surgical technique might also have an impact on RLNP.

In conclusion, the results of the present systematic review and meta-analysis suggested that IONM was associated with lower rates of RLNP and hoarseness and more effective lymphadenectomy after thoracoscopic esophagectomy for esophageal cancer. However, IONM was not associated with a significant benefit in preventing pneumonia and aspiration or reducing operation time and length of hospital stay.

\section{DATA AVAILABILITY STATEMENT}

The original contributions presented in the study are included in the article/supplementary material, further inquiries can be directed to the corresponding author/s.

\section{AUTHOR CONTRIBUTIONS}

XW: drafted the manuscript. BC: revised the manuscript. HG and XW: extracted the data and XW did the analysis. QH and YY: assessed the quality of the included studies. All authors contributed to the article and approved the submitted version.

\section{FUNDING}

The work was supported by Taizhou Municipal Science and Technology Bureau (No. 1801ky09) and the Medical Health Science and Technology Project of Zhejiang Provincial Health Commission (No. 2019KY773). The funding has no role in the design of the study and collection, analysis, interpretation of data and writing of the manuscript. 


\section{REFERENCES}

1. Fujita H, Sueyoshi S, Tanaka T, Fujii T, Toh U, Mine T, et al. Optimal lymphadenectomy for squamous cell carcinoma in the thoracic esophagus: comparing the short- and long-term outcome among the four types of lymphadenectomy. World J Surg. (2003) 27:571-9. doi: 10.1007/s00268-003-6913-z

2. Kang $\mathrm{CH}$, Kim YT, Jeon SH, Sung SW, Kim JH. Lymphadenectomy extent is closely related to long-term survival in esophageal cancer. Eur J Cardiothorac Surg. (2007) 31:154-60. doi: 10.1016/j.ejcts.2006. 10.033

3. Matsubara $\mathrm{T}$, Ueda $\mathrm{M}$, Abe $\mathrm{T}$, Akimori $\mathrm{T}$, Kokudo $\mathrm{N}$, Takahashi $\mathrm{T}$. Unique distribution patterns of metastatic lymph nodes in patients with superficial carcinoma of the thoracic oesophagus. Br J Surg. (1999) 86:669-73. doi: 10.1046/j.1365-2168.1999.01067.x

4. Jang HJ, Lee HS, Kim MS, Lee JM, Zo JI. Patterns of lymph node metastasis and survival for upper esophageal squamous cell carcinoma. Ann Thorac Surg. (2011) 92:1091-7. doi: 10.1016/j.athoracsur.2011.03.093

5. Tachimori Y, Nagai Y, Kanamori N, Hokamura N, Igaki H. Pattern of lymph node metastases of esophageal squamous cell carcinoma based on the anatomical lymphatic drainage system. Dis Esophagus. (2011) 24:33-8. doi: 10.1111/j.1442-2050.2010.01086.x

6. Shen Y, Zhang Y, Tan L, Feng M, Wang H, Khan MA, et al. Extensive mediastinal lymphadenectomy during minimally invasive esophagectomy: optimal results from a single center. J Gastrointest Surg. (2012) 16:715-21. doi: 10.1007/s11605-012-1824-7

7. Gockel I, Kneist W, Keilmann A, Junginger T. Recurrent laryngeal nerve paralysis (RLNP) following esophagectomy for carcinoma. Eur J Surg Oncol. (2005) 31:277-81. doi: 10.1016/j.ejso.2004. 10.007

8. Swanson SJ, Batirel HF, Bueno R, Jaklitsch MT, Lukanich JM, Allred $\mathrm{E}$, et al. Transthoracic esophagectomy with radical mediastinal and abdominal lymph node dissection and cervical esophagogastrostomy for esophageal carcinoma. Ann Thorac Surg. (2001) 72:1918-24; discussion 24-5. doi: 10.1016/S0003-4975(01)03203-9

9. van Sandick JW, van Lanschot JJ, ten Kate FJ, Tijssen JG, Obertop H. Indicators of prognosis after transhiatal esophageal resection without thoracotomy for cancer. J Am Coll Surg. (2002) 194:28-36. doi: 10.1016/S1072-7515(01)01119-X

10. Taniyama Y, Miyata G, Kamei T, Nakano T, Abe S, Katsura K, et al. Complications following recurrent laryngeal nerve lymph node dissection in oesophageal cancer surgery. Interact Cardiovasc Thorac Surg. (2015) 20:41-6. doi: 10.1093/icvts/ivu336

11. Pertl L, Zacherl J, Mancusi G, Gächter JN, Asari R, Schoppmann S, et al. High risk of unilateral recurrent laryngeal nerve paralysis after esophagectomy using cervical anastomosis. Eur Arch Otorhinolaryngol. (2011) 268:1605-10. doi: 10.1007/s00405-011-1679-7

12. Dralle H, Sekulla C, Lorenz K, Brauckhoff $M$, Machens A. Intraoperative monitoring of the recurrent laryngeal nerve in thyroid surgery. World J Surg. (2008) 32:1358-66. doi: 10.1007/s00268-008-9483-2

13. Dralle H, Sekulla C, Lorenz K, Nguyen Thanh P, Schneider R, Machens A. Loss of the nerve monitoring signal during bilateral thyroid surgery. Br J Surg. (2012) 99:1089-95. doi: 10.1002/bjs.8831

14. Alesina PF, Rolfs T, Hommeltenberg S, Hinrichs J, Meier B, Mohmand $\mathrm{W}$, et al. Intraoperative neuromonitoring does not reduce the incidence of recurrent laryngeal nerve palsy in thyroid reoperations: results of a retrospective comparative analysis. World J Surg. (2012) 36:1348-53. doi: 10.1007/s00268-012-1548-6

15. Dionigi G, Alesina PF, Barczynski M, Boni L, Chiang FY, Kim $\mathrm{HY}$, et al. Recurrent laryngeal nerve injury in video-assisted thyroidectomy: lessons learned from neuromonitoring. Surg Endosc. (2012) 26:2601-8. doi: 10.1007/s00464-012-2239-y

16. Kobayashi H, Kondo M, Mizumoto M, Hashida H, Kaihara S, Hosotani R. Technique and surgical outcomes of mesenterization and intraoperative neural monitoring to reduce recurrent laryngeal nerve paralysis after thoracoscopic esophagectomy: a cohort study. Int J Surg. (2018) 56:301-6. doi: 10.1016/j.ijsu.2018.05.738
17. Zhong D, Zhou Y, Li Y, Wang Y, Zhou W, Cheng Q, et al. Intraoperative recurrent laryngeal nerve monitoring: a useful method for patients with esophageal cancer. Dis Esophagus. (2014) 27:444-51. doi: 10.1111/j.1442-2050.2012.01414.x

18. Takeda S, Iida M, Kanekiyo S, Nishiyama M, Tokumitsu Y, Shindo $\mathrm{Y}$, et al. Efficacy of intraoperative recurrent laryngeal neuromonitoring during surgery for esophageal cancer. Ann Gastroenterol Surg. (2021) 5:83-92. doi: 10.1002/ags3.12394

19. Hikage M, Kamei T, Nakano T, Abe S, Katsura K, Taniyama $Y$, et al. Impact of routine recurrent laryngeal nerve monitoring in prone esophagectomy with mediastinal lymph node dissection. Surg Endosc. (2017) 31:2986-96. doi: 10.1007/s00464-016-5317-8

20. Fujimoto D, Taniguchi K, Kobayashi H. Intraoperative neuromonitoring during prone thoracoscopic esophagectomy for esophageal cancer reduces the incidence of recurrent laryngeal nerve palsy: a single-center study. Updat Surg. (2021) 73:587-95. doi: 10.1007/s13304-020-00967-4

21. Higgins JP, Thompson SG, Deeks JJ, Altman DG. Measuring inconsistency in meta-analyses. BMJ. (2003) 327:557-60. doi: 10.1136/bmj.327.7414.557

22. Wan X, Wang W, Liu J, Tong T. Estimating the sample mean and standard deviation from the sample size, median, range and/or interquartile range. BMC Med Res Methodol. (2014) 14:135. doi: 10.1186/1471-2288-14-135

23. Yuda M, Nishikawa K, Takahashi K, Kurogochi T, Tanaka Y, Matsumoto A, et al. A strategy for using intraoperative nerve monitoring during esophagectomy to prevent recurrent laryngeal nerve palsy. Anticancer Res. (2018) 38:1563-7. doi: 10.21873/anticanres.12385

24. Kawano F, Takeno S, Tashiro K, Hamada R, Miyazaki Y, Munakata S, et al. A study on the utility of intraoperative neurostimulation monitoring system for recurrent laryngeal nerve in esophagectomy. Dis Esophagus. (2018) 31:103. doi: 10.1093/dote/doy089.PS01.189

25. Tsang RK, Law S. Adaptation of continuous intraoperative vagus nerve stimulation for monitoring of recurrent laryngeal nerve during minimally invasive esophagectomy. World J Surg. (2016) 40:137-41. doi: 10.1007/s00268-015-3265-4

26. Nitta T, Kawai M, Kataoka J, Ohta M, Tashiro K, Ishibashi T. Combined intraoperative identification and monitoring of recurrent laryngeal nerve paresis during minimally invasive esophagectomy: surgical technique using nerve integrity monitoring for esophageal carcinoma. Case Rep Gastroenterol. (2020) 14:644-51. doi: 10.1159/000510209

27. Nakano $T$, Shibata $C$, Kamei T. Intraoperative recurrent laryngeal nerve monitoring in the thoracoscopic esophagectomy. Surg Endosc. (2018) 32:S593. doi: 10.1007/s00464-018-6181-5

28. Gelpke H, Grieder F, Decurtins M, Cadosch D. Recurrent laryngeal nerve monitoring during esophagectomy and mediastinal lymph node dissection. World J Surg. (2010) 34:2379-82. doi: 10.1007/s00268-010-0692-0

29. Ikeda $\mathrm{Y}$, Inoue $\mathrm{T}$, Ogawa $\mathrm{E}$, Horikawa $\mathrm{M}$, Inaba $\mathrm{T}$, Fukushima R. Recurrent laryngeal nerve monitoring during thoracoscopic esophagectomy. World J Surg. (2014) 38:897-901. doi: 10.1007/s00268-0132362-5

30. Staubitz JI, van der Sluis PC, Berlth F, Watzka F, Dette F, Läßig A, et al. Recurrent laryngeal nerve monitoring during totally robot-assisted Ivor Lewis esophagectomy. Langenbeck Arch Surg. (2020) 405:1091-9. doi: 10.1007/s00423-02001990-0

31. Ozawa S, Koyanagi K, Kazuno A, Yamamoto M, Ninomiya Y, Yatabe K. Study of continuous intraoperative vagus nerve stimulation for monitoring the recurrent laryngeal nerve function during thoracoscopic esophagectomy in a prone position for esophageal cancer. Surg Endosc. (2019) 33:S334. doi: 10.1007/s00464-019-06704-2

32. Kanemura T, Miyata H, Yamasaki M, Makino T, Miyazaki Y, Takahashi T, et al. Usefulness of intraoperative nerve monitoring in esophageal cancer surgery in predicting recurrent laryngeal nerve palsy and its severity. Gen Thorac Cardiovasc Surg. (2019) 67:1075-80. doi: 10.1007/s11748-019-01107-5

33. Kanekiyo S, Takeda S, Nishiyama M, Kitahara M, Iida M, Suzuki N, et al. Usefulness of intraoperative recurrent laryngeal nerve monitoring during thoracoscopic esophagectomy. Dis Esophagus. (2016) 29:92A.

34. Kobayashi HK, Kondo MK, Mizumoto MM, Uryuhara KU, Hashida H, Komori JK, et al. Prevention of recurrent laryngeal nerve paralysis after 
esophagectomy using NIM-response system. Surg Endosc Other Interv Tech. (2017) 31:S471. doi: 10.1007/s00464-017-5566-1

35. Wong IYH, Tsang RKY, Tong DKH, Chan SY, Chan KK, Wong C, et al. Continuous intraoperative vagus nerve stimulation for monitoring of recurrent laryngeal nerve function during lymphadenectomy in minimally invasive esophagectomy. Gastroenterology. (2017) 152:S1263. doi: 10.1016/S0016-5085(17)34210-5

36. Tong D, Tsang RKY, Chan SY, Law TT, Chan DKK, Wong IYH, et al. Lymphadenectomy with continous vagus nerve stimulation for recurrent laryngeal nerve monitoring in thoracoscopic esophagectomy. Dis Esophagus. (2016) 29:44A-5A.

37. Ikeda $\mathrm{Y}$, Inoue $\mathrm{T}$, Ogawam $\mathrm{E}$, Horikawa $\mathrm{M}$, Koide $\mathrm{T}$, Inaba $\mathrm{T}$, et al. Recurrent laryngeal nerve monitoring during thorachoscopic esophagectomy in the prone position. Dis Esophagus. (2012) 25:101A. doi: 10.1111/j.1442-2050.2012.01405.x

38. Schmidt J, Irouschek A, Heinrich S, Oster O, Klein P, Birkholz T. Recurrent laryngeal nerve monitoring during esophagectomy and mediastinal lymph node dissection: a novel approach using a single-lumen endotracheal EMG tube and the EZ-blocker. World J Surg. (2012) 36:2946-7; author reply 8. doi: 10.1007/s00268-0121700-3

39. Wang Z, Mao Y, Gao S, Li Y, Tan L, Daiko H, et al. Lymph node dissection and recurrent laryngeal nerve protection in minimally invasive esophagectomy. Ann N Y Acad Sci. (2020) 1481:20-9. doi: 10.1111/nyas. 14427

40. Garas G, Kayani B, Tolley N, Palazzo F, Athanasiou T, Zacharakis E. Is there a role for intraoperative recurrent laryngeal nerve monitoring during high mediastinal lymph node dissection in threestage oesophagectomy for oesophageal cancer? Int J Surg. (2013) 11:370-3. doi: 10.1016/j.ijsu.2013.03.011

41. Wong IYH, Zhang RQ, Tsang RKY, Chan FSY, Chan KK, Wong C, et al. Continuous and intermittent recurrent laryngeal nerve monitoring improves superior mediastinal dissection for esophageal squamous cell carcinoma. Gastroenterology. (2020) 158:S1506. doi: 10.1016/S0016-5085(20)34435-8

42. Kamei T, Taniyama Y, Okamoto H. Thoracoscopic esophagectomy with intraoperative nerve monitoring for esopgaeal cancer. Surg Endosc. (2019) 33:S552. doi: 10.1007/s00464-019-07109-x

43. Lee S, Fujiwara Y, Hashiba R, Gyobu K, Inazu D, Naka R, et al. Efficacy of intraoperative recurrent laryngeal nerve monitoring during upper mediastinal lymph node dissection in thoracoscopic radical esophagectomy. Dis Esophagus. (2018) 31:125. doi: 10.1093/dote/doy089.PS02.017

44. Kobayashi H, Kondo M, Mizumoto M, Kita R, Masui H, Kitano S, et al. Mesenterization and intra-operative neural monitoring to reduce the recurrent laryngeal nerve paralysis after thoracoscopic esophagectomy in prone position. Surg Endosc Other Interv Tech. (2018) 32:S251.

45. Yu Hong Wong I, King Yin Tsang R, Kwan Kit Chan D, Lai Yin Wong C, Ting Law T, King Hung Tong D, et al. PS01.138: experience from
102 patients with continuous intraoperative vagus nerve stimulation during minimally invasive esophagectomy. Dis Esophagus. (2018) 31(Supplement_1):89. doi: 10.1093/dote/doy089.PS01.138

46. Kobayashi H, Mizumoto M, Kondo M, Kita R, Masui H, Kitano S, et al. PS01.238: mesentery-oriented lymph nodes dissection and intraoperative neural monitoring to reduce the postoperative recurrent laryngeal nerve paralysis in esophagectomy. Dis Esophagus. (2018) 31(Supplement_1):117.doi: 10.1093/dote/doy089.PS01.238

47. Yuda M, Nishikawa K. Intraoperative Nerve Monitoring System during Esophagectomy to Prevent Recurrent Laryngeal Nerve Palsy. Kyobu Geka. (2018) 71:886-9.

48. Zhu W, Yang FJC. Application of recurrent laryngeal nerve detector in the neck anastomosis of upper or middle-thoracic esophageal carcinoma. Cancer Res Clin. (2018) 30:233-6. doi: 10.3760/cma.j.issn.1006-9801.2018.04.004

49. Malassagne B, Tiret E, Duprez D, Coste J, de Sigalony JP, Parc R. Prognostic value of thoracic recurrent nerve nodal involvement in esophageal squamous cell carcinoma. J Am Coll Surg. (1997) 185:2449. doi: 10.1016/S1072-7515(97)00046-X

50. Watanabe H, Kato H, Tachimori Y. Significance of extended systemic lymph node dissection for thoracic esophageal carcinoma in Japan. Recent Results Cancer Res. (2000) 155:123-33. doi: 10.1007/978-3-642-59600-1_13

51. Hulscher JB, van Sandick JW, Devriese PP, van Lanschot JJ, Obertop H. Vocal cord paralysis after subtotal oesophagectomy. Br J Surg. (1999) 86:15837. doi: 10.1046/j.1365-2168.1999.01333.x

52. Bollschweiler E, Schröder W, Hölscher AH, Siewert JR. Preoperative risk analysis in patients with adenocarcinoma or squamous cell carcinoma of the oesophagus. Br J Surg. (2000) 87:110610. doi: 10.1046/j.1365-2168.2000.01474.x

Conflict of Interest: The authors declare that the research was conducted in the absence of any commercial or financial relationships that could be construed as a potential conflict of interest.

Publisher's Note: All claims expressed in this article are solely those of the authors and do not necessarily represent those of their affiliated organizations, or those of the publisher, the editors and the reviewers. Any product that may be evaluated in this article, or claim that may be made by its manufacturer, is not guaranteed or endorsed by the publisher.

Copyright (C) 2021 Wang, Guo, Hu, Ying and Chen. This is an open-access article distributed under the terms of the Creative Commons Attribution License (CC BY). The use, distribution or reproduction in other forums is permitted, provided the original author(s) and the copyright owner(s) are credited and that the original publication in this journal is cited, in accordance with accepted academic practice. No use, distribution or reproduction is permitted which does not comply with these terms. 